African Journal of Educational Studies in Mathematics and Sciences Vol. 15, No. 2., 2019

\title{
An Analysis of Prospective Teachers' Mathematical Reasoning on Number Concepts
}

\author{
A. ${ }^{1}$ Mukuka, O. ${ }^{2}$ Shumba, S. ${ }^{3}$ Balimuttajjo \& V. ${ }^{4}$ Mutarutinya
}

\begin{abstract}
This paper presents and discusses results of a case study that was carried out to understand the mathematical reasoning of 73 second year student teachers at a university in Zambia. The paper also demonstrates why it is important to develop the reasoning abilities of mathematics student teachers during their initial training programs. The questionnaire items presented to student teachers required them to justify the validity of selected algebraic statements and arguments on odd and even numbers. Factors that influenced participants' modes of argumentation were also identified, clearly highlighting their implications for mathematics teacher education. Findings of the study revealed that $70 \%$ of the participants gave explanations that were aligned to empirical or inductive mode of argumentation while $7 \%$ used the analytical or deductive argumentation mode. The rest of the participants gave explanations that did not reflect valid mathematical justification of the given algebraic statements and arguments. These results clearly indicate that only the minority of participants exhibited adequate understanding of representing odd and even numbers in general form. Analysing and developing prospective teachers' mathematical reasoning abilities are necessary to anticipate how they would practice when they are professionally qualified.
\end{abstract}

Keywords: inductive and deductive arguments; mathematical reasoning; number concepts; prospective teachers

\section{Introduction}

Mathematics education research has persistently affirmed that the further development of mathematics depends on reasoning (Aricha-Metzer \& Zaslavsky, 2017; Ball \& Bass, 2003; Brodie, 2010; Ellis, Özgür, \& Reiten, 2018; Ross, 1998). Henriques (2013) regards the ability to reason mathematically as the gathering and mastery of specific knowledge of mathematical content. In the context of this paper, conjecturing, justification and generalisation are considered as key attributes of mathematical reasoning. Similarly, the National Council of Teachers of Mathematics [NCTM] (2000) highlights that mathematical reasoning occurs only when students are able to state and test conjectures as well as building arguments to justify those conjectures.

The above argument demonstrates that reasoning is an indispensable component of mathematics and it is one of the features that distinguishes mathematics from other disciplines. According to Mata-pereira and Ponte (2017, p.170), "students engaged in mathematical reasoning gain familiarity with the mathematical language and increase their conceptual understanding". In

\footnotetext{
${ }^{1}$ Angel Mukuka. African Centre of Excellence for Innovative Teaching and Learning Mathematics \& Science, University of Rwanda, College of Education. Email: mukukaangel@yahoo.com

${ }^{2}$ Overson Shumba, Centre for Academic Development, \& School of Mathematics and Natural Sciences, Copperbelt University, Kitwe, Zambia.

${ }^{3}$ Sudi Balimuttajjo, Department of Educational Foundations and Psychology, Mbarara University of Science \& Technology, Uganda.

${ }^{4}$ Vedaste Mutarutinya, University of Rwanda - College of Education (UR-CE), School of Education, Department of Mathematics, Science and Physical Education
}

Open Access article distributed under the terms of the Creative Commons Attributions License [CC BY-NC-ND 4.0] http://creativecommons.org/licenses/by-nc-nd/4.0. DOI: https://dx.doi.org/10.4314/ajesms.v15i2.10 


\section{A. Mukuka, O. Shumba, S. Balimuttajjo \& V. Mutarutinya}

addition, Ball \& Bass (2003) concluded that the ability to reason mathematically opens up opportunities for learners to make generalizations rather than relying on specific instances when justifying the validity of mathematical statements. This points to the need to focus on developing reasoning among prospective teachers in a quest to raise standards in the teaching and learning of mathematics.

Despite being an indispensable component of mathematics, enhancing students' mathematical reasoning has been quite challenging for mathematics educators at different levels of education (Brodie, 2010; Ellis et al., 2018; Henriques, 2013; Knipping, 2004). In laying a foundation for further research on investigating ways through which students' mathematical reasoning ability could be enhanced in Zambia and other settings, this study attempted to understand the reasoning abilities of prospective teachers on number concepts and its implications for mathematics teacher education.

\section{Purpose of the study}

This study is rationalized on the basis of its attempt to understand prospective teachers' ability to construct and evaluate valid mathematical justifications on number concepts. This paper explored two specific objectives:

i. To determine student teachers' argumentation modes when developing and verifying algebraic conjectures on odd and even numbers.

ii. To findout the reasons given by student teachers when explaining their understanding of what constitutes valid mathematical justification.

Our belief is that understanding how student teachers justify, assess and evaluate algebraic statements on number concepts is important to anticipate how they will practice when they are professionally qualified.

\section{Theoretical perspectives.}

Guiding our perspective is the "process aspects" of mathematical reasoning, a model recently developed by Jeannotte \& Kieran (2017). Among the various mathematical reasoning processes that have been documented in literature, Jeannotte \& Kieran (2017) classified them into two categories namely; the search for similarities and differences, and validation. Five distinct mathematical reasoning processes emerged under the first category - That is, generalizing, conjecturing, identifying a pattern, comparing and classifying. In the second category (I.e. validating), three distinct mathematical reasoning processes were identified. These include justifying, proving and formal proving. Validating has been thought to be a mathematical reasoning process that aims at demonstrating or establishing the accuracy of a mathematical statement or argument.

Other scholars (e.g. Ellis et al., 2018; Henriques, 2013; Moru, Nchejane, Ramollo, \& Rammea, 2017; Selden \& Selden, 2015) have also emphasised the importance of each of the above mentioned mathematical reasoning processes in arriving at valid conclusions during the development, investigation and evaluation of mathematical conjectures and arguments. Based on the above mentioned model and other previous studies, we considered conjecturing, justifying and generalizing as key aspects of mathematical reasoning.

\section{Methodology}

Data for this descriptive survey research were collected at one of the universities in Zambia. Seventy-three (73) second year mathematics student teachers were available for the study. While Mukuka \& Shumba (2016) reported on students teachers' algebraic proof conceptions with special focus on its implications for school-based assessment of mathematical learning, this paper focuses 
on the implications of student teachers' mathematical reasoning for mathematics teacher education. The paper analyses student teachers' responses to two tasks on even and odd numbers. Task one is concerned with student teachers' justification of whether or not the sum of an odd number and an even number turns out to be odd. Task two tested the student teachers' ability to assess and select the most convincing proof argument regarding the divisibility of the sum of three consecutive even numbers by 6 . Development of the questionnaire items were based on previous studies (see Varghese, 2009; Janelle, 2014). This was done to ensure that only tasks that have been previously validated and checked for reliability were considered.

Data were analysed into categories of meaning using descriptive statistics such as percentages, mean and standard deviation. These categories focussed on empirical or inductive reasoning versus analytical or deductive reasoning. Justification through inductive reasoning was based on citing numerical values to expressions or giving examples of numbers that can satisfy a given statement or expression. On the other hand, analytical or deductive reasoning was based on logical deductions reflecting mathematical relationships and justified inferences. Factors that influenced participants' modes of argumentation were also identified, clearly highlighting their implications for mathematics teacher education.

Although both forms of reasoning are useful in various ways, some scholars (such as ArichaMetzer \& Zaslavsky, 2017; Zaslavsky, Nickerson, Stylianides, Kidron, \& Winicki-Landman, 2012) have indicated some weaknesses of inductive reasoning in comparison to deductive reasoning. One of those weaknesses is that it may be incomplete at times because inferences are made on the basis of checking few examples or instances that satisfy a particular claim. It has been argued that this can lead to false conclusions even with accurate observations. In view of this, the present study takes inductive reasoning as a way of gaining a better understanding of mathematical conjectures or claims, whose validity could be established through deductive reasoning.

\section{Results}

Student teachers' explanations regarding the validity of an algebraic statement.

Firstly, the participants were required to state whether the sum of an odd and an even number is odd or not. Secondly, they were required to give reasons for their choices. Majority of them (n= 70 or $95.9 \%$ ) agreed with the statement while ( 3 or $4.1 \%$ ) disagreed. Figure 1 illustrates four categories that emerged from 69 responses regarding student teachers' explanations to justify why the statement is true. Majority of them $(n=48$ or $70 \%)$ gave explanations that were classified as inductive reasoning while $9(13 \%)$ of the responses reflected some misunderstandings of what constitutes an odd number and an even number. 


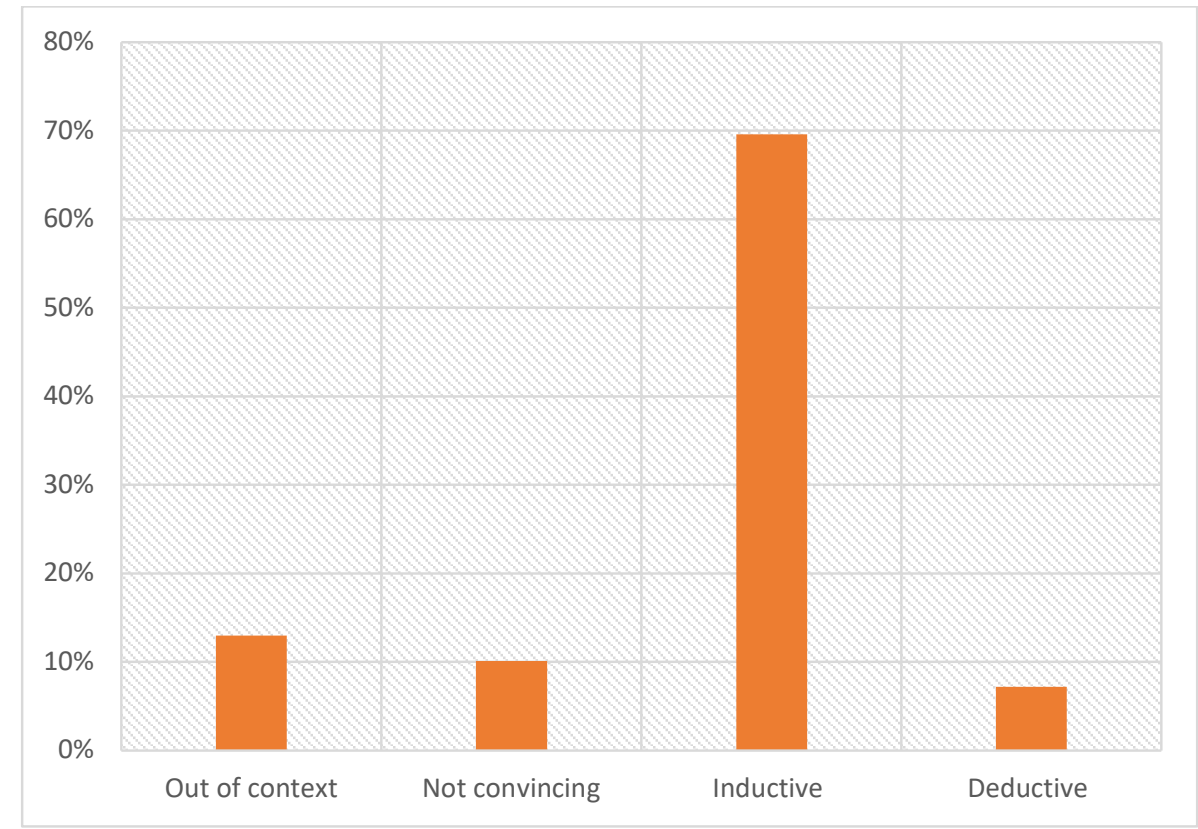

Figure 1: Student teachers' categories of explanations to justify why the statement is true

Results displayed in Figure 1 also revealed that 7(10\%) of the respondents gave explanations that were not sufficient to warrant valid mathematical justification and were classified as "not convincing". Only 5 or $7 \%$ justified their choice using a deductive mode of reasoning. Overall, most of the respondents regarded explanations by citing specific numerical cases from a specified domain as being sufficient to warrant valid mathematical justification.

Table 1 illustrates specific examples of the explanations by some participants for each of the four categories highlighted above. The first explanation in Table 1 was categorised as out of context because the student teacher indicated that an even number is also an odd number. Merely stating that odd numbers start from 1 does not constitute valid mathematical justification regarding the validity of the statement in question. The explanation offered in the second category (refer to Table 1) seems to dwell more on the issue of remainders. In as much as the student was right to mention that odd numbers leave a remainder of 1 when divided by 2 , the explanation given did not address the question at hand. The two examples of explanations displayed in the third category were classified as inductive reasoning because the participants justified by merely citing specific numeric cases that would satisfy the given statement.

The fourth explanation in Table 1, represents a deductive justification that followed a logical chain of steps to arrive at the required conclusion. The explanation offered here reflects the general representation of both odd and even numbers. The layout and presentation of the explanation also reflects valid mathematical justification of a given conjecture. Unfortunately, very few student teachers $(n=5$ or $7 \%)$ managed to produce explanations of this nature. 
Table 1: Samples of student teachers' explanations for the validity of a given algebraic statement

\begin{tabular}{ll}
\hline Category & Example of students' choices and explanations for each category \\
\hline Out of context & $\begin{array}{l}\text { Choice: True } \\
\text { Explanation: This is because the even number is also odd number. Odd numbers are } \\
\text { numbers that starts from 1. So the statement is true. }\end{array}$ \\
\hline
\end{tabular}

Not convincing Choice: True

Explanation: This because if a number is not divisible by 2, no matter how many numbers which are divisible by 2 are added to it. The remainder that makes it not to be divisible by two always remains. The remainder 1 . In other words the remainder one, needs a number which will have a remainder of one also if it can be changed to being even or otherwise, hence the statement is true

$\begin{array}{ll}\text { Inductive } & \text { (i). Choice: } \text { True } \\ \text { reasoning } & \text { Explanation: Because } 22+11=33 \text { and } 7+6=13\end{array}$

33 and 13 are odd

(ii). Choice: True

Explanation: This is because an odd number has a remainder when divided by 2. It's because of this remainder that makes the sum of this even and odd number to be odd. e.g. 4 is even and 5 is and odd number. When you add the two, which is $4+5=9$ which odd. This is because when you divide an odd number, say

$5 / 2=2$ remainder 1 . It is this 1 which turns the sum of odd number and even to be odd.

Deductive reasoning

\section{Choice: True}

Explanation: Going by the definition of an odd and an even number, Let us assume that $a=2 n$ is even, then $\mathrm{b}=2 \mathrm{n}+1$ must be odd provided $\mathrm{n}$ is a positive integer or natural number. Odd + Even $=a+b=2 n+2 n+1$. By factoring out 2 , we can get 2 $(n+n)+1=2(2 n)+1$. Since $\mathrm{n}$ is a positive integer, we expect $2 n$ to be a postive integer too. If we let $c=2 n$, our final answer is $2 c+1$ which represents the general form of an odd number. Therefore, the statement is true.

Respondents' preferred written proof arguments of a given algebraic conjecture.

Respondents were requested to rate three written proof arguments to justify whether the sum of any three consecutive even numbers is always divisible by 6 . Three written proof arguments $\mathrm{A}, \mathrm{B}$, and $\mathrm{C}$ were presented to the participants, who were required to evaluate each one of them and give their ratings from 1 (not convincing) to 4(Completely convincing).

Arguments A and B were aligned to empirical or inductive reasoning, which was characterised by testing of several numeric cases to draw a conclusion. On the other hand, argument $\mathrm{C}$ was based on deductive reasoning, which follows a logical sequence of steps to arrive at a conclusion.

Table 2 summarises the results regarding respondents' choices of the written proof arguments. The responses are summarised in terms of the mean (M), standard deviation (SD) and the 


\section{A. Mukuka, O. Shumba, S. Balimuttajjo \& V. Mutarutinya}

percentages of student teachers who responded to each argument following the criteria prescribed above.

Results displayed in Table 2 clearly indicate that the inductive argument A was highly rated $(\mathrm{M}=$ $3.60, \mathrm{SD}=.69$ ) implying that student teachers were completely convinced that the argument constitutes a valid mathematical justification. Another inductive argument B received high ratings $(\mathrm{M}=3.31, \mathrm{SD}=.87)$, an indication that student teachers were mostly convinced that argument $\mathrm{B}$ reflected a valid mathematical justification of a given statement. On average student teachers endorsed argument $\mathrm{C}(\mathrm{M}=2.40, \mathrm{SD}=.68)$ as a slightly convincing argument. The values of standard deviations displayed in Table 2 further reflect that student teachers' ratings on each of the three proof arguments were not too deviant from the mean.

Table 2: Respondents' assessment and validation of the written proof arguments of a given algebraic conjecture

\begin{tabular}{cccccccc}
\hline \multirow{2}{*}{ Argument } & Count (n) & $\boldsymbol{M}$ & $\boldsymbol{S D}$ & \multicolumn{5}{c}{ Ratings (\%) } \\
\cline { 5 - 8 } & & & & $\boldsymbol{1}$ & $\mathbf{2}$ & $\mathbf{3}$ & $\mathbf{4}$ \\
\hline $\mathrm{A}$ & 67 & 3.60 & .70 & 0 & 11.9 & 16.4 & 71.6 \\
$\mathrm{~B}$ & 64 & 3.31 & .87 & 4.7 & 12.5 & 29.7 & 53.1 \\
C & 62 & 2.40 & .68 & 17.7 & 21 & 14.5 & 46.8 \\
\hline
\end{tabular}

In order to compare related findings, which consistently show how A and B are rated highly, results show that $\mathrm{A}$ and $\mathrm{B}$ were rated as more convincing with $71.6 \%$ and $53.1 \%$ respectively, which are both greater than the ratings for $\mathrm{C}$ with $46.8 \%$. On the other hand, lower rates of $0 \%$ and $4.7 \%$ were given to $\mathrm{A}$ and $\mathrm{B}$ as arguments that are "not convincing" while $\mathrm{C}$ is seen as highly "not convincing" with $17.7 \%$. Most student teachers endorsed inductive arguments as being valid because they found it easy to interpret them since they involved justification by citing specific numbers.

A further qualitative analysis of students' written responses revealed other factors that might have led to that limited understanding of deductive mathematical justification. These factors were attributed to (i) the perception by most student teachers that mathematics is all about numbers, (ii) the way they were taught in secondary schools, where memorization of facts and procedures in order to pass the final examination was lauded by most teachers, and (iii) lack of exposure to deductive modes of argumentation when investigating mathematical conjectures.

\section{Discussion of the findings}

In the context of this study, the majority of student teachers aligned themselves more with inductive reasoning than with deductive reasoning. Most student teachers constructed or preferred inductive arguments as opposed to deductive ones. We concur with Knuth, Zaslavsky, \& Ellis (2017) that empirical evidence has value because it helps in conjecturing as well as providing insights into matters to do with validity of a given mathematical statement. However, some scholars (e.g., Aricha-Metzer \& Zaslavsky, 2017; Yopp, 2015) have argued that empirical evidence alone is not sufficient for viable argumentation because conclusions are made on the basis of citing specific instances instead of drawing inferences from a general premise. In line with the observation by Herbert et al. (2015), this ought to be one of the compelling grounds for mathematics teacher educators and other stakeholders to consider embedding mathematical reasoning in mathematics teacher education curriculum. We are of the view that the effectiveness of teachers may be partly influenced by their initial training. Therefore, the content and pedagogy 
taught in courses taken by prospective teachers at their colleges and universities should be aligned with the demands of school mathematics curriculum.

On proof validation, the majority of student teachers considered an argument valid, as long as the cited examples or numerical cases satisfied the given mathematical statement. A 1987 review by Fischbein recognised this tendency as an inhibiting factor in students' transition from inductive to deductive argumentation and justification (as cited in Aricha-Metzer \& Zaslavsky, 2017, examples in proving, para. 2). In view of this, mathematics teacher educators should consider creating classroom environments aimed at developing the mathematical reasoning abilities of the teachers in making to increase their mathematical knowledge and problem-solving skills. This will not only raise student teachers' achievement levels in mathematics but will also have a positive impact on their future teaching practices. Selden \& Selden (2015) argue that "holders of bachelor's degrees in mathematics are normally expected, not only to know considerable mathematics content, but also to be able to construct moderately complex proofs and to solve moderately non-routine problems"(p.146).

Although the majority of student teachers validated proof arguments by empirical justification, results indicate that some of them chose analytical or deductive arguments. This suggests the need for the development of student teachers' ability to use inductive reasoning as a way of gaining a better understanding of mathematical conjectures whose validity could be established deductively (Knuth et al., 2017). Some previous studies (e.g. Ayalon \& Hershkowitz, 2017; Moru et al., 2017; Mueller, Yankelewitz, \& Maher, 2014; Yopp, 2015) have also demonstrated the need for teachers at different levels of education to establish classroom norms and standards for promoting mathematical reasoning.

From the way student teachers justified their choices of proof arguments, the overall impression is that secondary school and first year university mathematics might have provided them with inadequate opportunities to learn how to come up with coherent arguments in justifying mathematical conjectures. This finding is consistent with Jones' (1997) review, which suggests that past school experiences of student teachers might deprive them of any possibility for producing reasoned arguments. Although this is not the whole story, it presents mathematics teacher educators with a challenge on how to improve the quality of mathematics education. One of the ways to address this challenge is for mathematics teacher training programmes to embrace mathematical reasoning as a key proficiency. They must stress more on improving student teachers' mathematical reasoning abilities and lessen the over-reliance on rote memorization. Professional documents such as schemes of work and lesson plans prepared by student teachers during their teaching practice (Njiku, 2016), should also incorporate classroom activities requiring learners to reason logically.

Based on the results displayed in Table 1, it was also observed that some participants gave explanations that could not be classified as valid mathematical justification. This is partly due to challenges associated with language and misconceptions about odd and even numbers. A similar study by Knipping (2004) also found that most of the participants (students) could not present their arguments in a logical manner due to difficulties with language and failure to communicate mathematically. In this sense, future teachers of mathematics ought to be provided with classroom opportunities aimed at building their mathematical thinking and expression. This is not only necessary for mathematics classrooms but for communication and problem-solving skills needed in other natural sciences like physics and work places (Kanamugire, Yadav, \& Mbonyiryivuze, 2019). Assessment of both the written and spoken words of teachers in making should take centre 


\section{A. Mukuka, O. Shumba, S. Balimuttajjo \& V. Mutarutinya}

stage in everyday classroom activities as that would enable them to replicate similar practices when they become professionally qualified.

\section{Conclusion}

There are many reasons for which enhancing prospective teachers' mathematical reasoning abilities can contribute to the development of mathematics education in Zambia and the entire continent of Africa. Not only is it a vehicle for developing logical thinking, it can provide student teachers with rich opportunities to recognise and solve real world problems. The challenge for those involved in mathematics teacher training is on how to enhance the role of mathematical reasoning in the classroom. Finding ways of using mathematical reasoning as a vehicle for promoting mathematical understanding ought to be cherished by mathematics teachers and teacher educators. The assessment and instructional approaches adopted in those classrooms should enable the teachers in making to appreciate the relationship between inductive and deductive reasoning. Both the shortcomings and strengths of inductive and deductive reasoning ought to be discussed during class sessions so as to raise awareness among prospective teachers on how the two modes of reasoning can complement each other.

\section{References}

Aricha-Metzer, I., \& Zaslavsky, O. (2017). The nature of students' productive and non-productive example-use for proving. Journal of Mathematical Behavior. https://doi.org/10.1016/j.jmathb.2017.09.002

Ayalon, M., \& Hershkowitz, R. (2018). Mathematics teachers ' attention to potential classroom situations of argumentation. Journal of Mathematical Behavior, 49, 163-173. https://doi.org/10.1016/j.jmathb.2017.11.010

Ball, D. L., \& Bass, H. (2003). Making Mathematics Reasonable in School. In W. Kilpatrick, G. Martin, \& S. Deborah (Eds.), A Research Companion to Principles and Standards for School Mathematics (pp. 27-44). The National Council of Teachers of Mathematics.

Brodie, K. (2010). Teaching Mathematical Reasoning in Secondary School Classrooms. New York: Springer Science \& Business Media Dordrencht. https://doi.org/10.1007/978-0-38709742-8

Ellis, A., Özgür, Z., \& Reiten, L. (2018). Teacher moves for supporting student reasoning. Mathematics Education Research Journal. https://doi.org/10.1007/s13394-018-0246-6

Henriques, A. C. (2013). Developing Students' Mathematical Reasoning: A Challenging Task. Retrieved from www.atomiumculture.eu

Herbert, S., Vale, C., Bragg, L. A., \& Loong, E. (2015). A framework for primary teachers ' perceptions of mathematical reasoning. International Journal of Educational Research, 74, 26-37. https://doi.org/10.1016/j.ijer.2015.09.005

Herbert, S., Vale, C., Bragg, L. A., Loong, E., \& Widjaja, W. (2015). A framework for primary teachers' perceptions of mathematical reasoning. International Journal of Educational Research, 74. https://doi.org/10.1016/j.ijer.2015.09.005

Janelle, J. (2014). Proof conceptions of calculus graduate students. University of Maine. Retrieved from https://digitalcommons.library.umaine.edu/etd/2101

Jeannotte, D., \& Kieran, C. (2017). A conceptual model of mathematical reasoning for school mathematics. Educational Studies in Mathematics, 96(1), 1-16. https://doi.org/10.1007/s10649-017-9761-8 
African Journal of Educational Studies in Mathematics and Sciences Vol. 15, No. 2., 2019

Jones, K. (1997). Student teachers' conceptions of mathematical proof. Mathematics Education Review, 9, 21-32.

Kanamugire, C., Yadav, L. L., \& Mbonyiryivuze, A. (2019). Tutors' perceptions about science curriculum reforms and challenges for their implementation in Teacher Training Colleges in Rwanda. African Journal of Educational Studies in Mathematics and Sciences, 15(1), 101116. https://doi.org/10.4314/ajesms.v15i1.9

Knipping, C. (2004). Challenges in teaching mathematical reasoning and proof - Introduction. ZDM - International Journal on Mathematics Education, 36(5), 127-128. https://doi.org/10.1007/BF02655664

Knuth, E., Zaslavsky, O., \& Ellis, A. (2017). The role and use of examples in learning to prove. Journal of Mathematical Behavior. https://doi.org/10.1016/j.jmathb.2017.06.002

Kramarski, B., \& Mevarech, Z. R. (2003). Enhancing Mathematical Reasoning in the Classroom: The Effects of Cooperative Learning and Metacognitive Training. American Educational Research Journal, 40(1), 281-310. https://doi.org/10.3102/00028312040001281

Mata-Pereira, J., \& da Ponte, J. P. (2017). Enhancing students' mathematical reasoning in the classroom: teacher actions facilitating generalization and justification. Educational Studies in Mathematics, 96(2), 169-186. https://doi.org/10.1007/s10649-017-9773-4

Moru, E. K., Nchejane, J., Ramollo, M., \& Rammea, L. (2017). University Undergraduate Science Students' Validation and Comprehension of Written Proof in the Context of Infinite Series. African Journal of Research in Mathematics, Science and Technology Education, 21(3), 256270. https://doi.org/10.1080/18117295.2017.1369218

Mueller, M., Yankelewitz, D., \& Maher, C. (2014). Teachers Promoting Student Mathematical Reasoning. The Research Council on Mathematics Learning, 7(2), 1-20.

Mukuka, A., \& Shumba, O. (2016). Zambian University Student Teachers' Conceptions of Algebraic Proofs. Journal of Education and Practice, 32(7), 157-171.

National Council of Teachers of Mathematics. (2000). Principles and standards for school mathematics. Reston, VA.

Njiku, J. (2016). School Based Professional Support to Student Teachers in Preparation of Teacher Professional Documents. Voice of Research, 5(3), 1-5.

Ross, K. A. (1998). Doing and proving: The place of algorithms and proof in school mathematics. The American Mathematical Monthly, 3(105), 252-255. https://doi.org/10.1080/00029890.1998.12004875

Selden, A., \& Selden, J. (2015). Validations of proofs as a type of reading and sense-making. In K. Beswick, T. Muir, \& J. Wells (Eds.), Proceedings of the 39th conference of the International Group of Psychology of Mathematics Education (pp. 145-152). Hobart, Australia: Psychology of Mathematics Education (PME).

Varghese, T. (2009). Secondary-level student teachers' conceptions of mathematical proof. Issues in the Undergraduate Mathematics Preparation of School Teachers, 1(June), 1-14. Retrieved from http://eric.ed.gov/?id=EJ859284

Yopp, D. A. (2015). The Journal of Mathematical Behavior Prospective elementary teachers ' claiming in responses to false generalizations. Journal of Mathematical Behavior, 39, 79-99. 
An analysis of prospective teachers' mathematical reasoning on number concepts

A. Mukuka, O. Shumba, S. Balimuttajjo \& V. Mutarutinya

https://doi.org/10.1016/j.jmathb.2015.06.003

Zaslavsky, O., Nickerson, S. D., Stylianides, A. J., Kidron, I., \& Winicki-Landman, G. (2012). The Need for Proof and Proving: Mathematical and Pedagogical Perspectives. In Proof and Proving in Mathematics Education (pp. 215-229). https://doi.org/10.1007/978-94-007-21296 